\title{
Action at ACEN
}

\author{
Nancy Lefebre, RN, MScN
}

Chief Clinical Executive and Senior Vice President, Saint Elizabeth

President, Academy of Canadian Executive Nurses

Staying the Course It's hard to believe that my journey as ACEN's president is halfway through! Some days it has been hard to travel the choppy waters, but what has helped me stay the course is a clear vision and an evolving map. Today, nursing leaders continue to face a multitude of challenging issues, but I think we underestimate the influence we can have on transforming the healthcare system. In a previous column (Lefebre 2012), I spoke about the need to have courageous conversations with people to ensure a common vision with a range of perspectives. This requires input from those involved in clinical practice, education, research and policy, as well as clients. Collectively, they inform us about the lay of the land, where we need to go and how we need to adapt to reflect their needs and wishes.

So in setting our course towards the horizon, ACEN has been playing a key role in connecting nursing leaders across the country and keeping them up to date regarding current and emerging issues in Canada. One such forum for sharing has been the Cross Country Check Up (CCCU). This year we hosted three CCCUs, with the first one held in April 2012. Entitled "Across the Nation," this session focused on the current state of healthcare reform across the country. Presentations by nurse executives Noreen Linton (Alberta Health Services), Lori Lamont (Winnipeg Regional Health Authority), Pina Lariccia (McGill University Health Centre) and Katherine Chubbs (Eastern Health) revealed a variety of similar and diverse initiatives taking place across the country.

The second Check Up looked at the current state of nursing informatics in Canada. Pat Rothney, president-elect of the Canadian Nursing Informatics Association (CNIA), discussed the many activities that are taking place throughout Canada in this area. Cheryl Reid-Haughian, director professional practice, knowledge and innovation, Paramed Home Healthcare, who spoke at the CNIA Strategic Planning day on behalf of ACEN, emphasized the importance of nursing leadership in nursing infor- 
matics and discussed potential strategies required to advance the field, including establishing nursing informatics as a specialty through the Canadian Nurses Association (CNA) and the creation of governance structures, education and resources.

The emphasis of our most recent Cross Country Check Up was on developing leadership and management behaviours for implementing clinical practice guidelines. As one of the goals of ACEN is to contribute to the creation of new knowledge in nursing, scholarships have been provided to candidates engaged in nursing doctoral programs. One such scholarship was awarded in 2008 to Wendy Gifford, RN, $\mathrm{PhD}$, assistant professor, University of Ottawa and senior research associate at Saint Elizabeth, to focus on the impact of leadership on the use of best practice guidelines. The scholarship has not only assisted Dr. Gifford in pursuing research in the area of implementation science, but has also created a foundation for knowledge that supports her in further developing this program of research with an international team of experts from Sweden, the United States and Canada.

One factor that contributes to the connection of nursing leaders from across the country is an expansion in the depth and breadth of our membership. I am pleased to report that ACEN currently has representation from all provinces in Canada. In addition, we now have members who represent the entire healthcare continuum from academia, research and public health, and from long-term, home, community and acute care. While this diversity is new for ACEN, we believe that it is critical to have members from the full spectrum of the health system, given the key role of nursing leaders in health system transformation.

\section{Moving in the Right Direction}

In addition to creating and exchanging knowledge, we have been moving forward in the policy arena through initiatives such as the National Nursing Report Card. The National Nursing Quality Report in Canada (NNQR-C) project, spearheaded by ACEN and the CNA, is creating a set of input, process and outcome indicators that will be collected nationally in acute, community, mental health and long-term care settings. With input from ACEN leaders, indicators and their definitions have been agreed upon and are consistent with the Canadian Patient Safety Institute, C-HOBIC and RNAO Best Practice definitions. To test the process, 10 sites from acute care, complex continuing care and mental health units in Saskatchewan, Manitoba, Ontario and Quebec have volunteered to be part of a pilot project. Data will be collected on indicators, work environment and system usability and displayed through a dashboard application within the healthcare settings. This approach will allow organizations to benchmark, use data to influence policy directions and improve client outcomes (VanDeVelde-Coke et al. 2012). Once the data are reviewed, our next goal is to begin a "think tank" discussion on the sustainability of the National Nursing Report. 


\section{What's the Next Destination?}

What is next in our journey?... Well, this is the question that ACEN Leadership and Policy Committee members have been focusing on this year. The committee feels that our number one priority is leadership development. Currently, we are asking ourselves how we can contribute to leadership development in a way that provides the needed skills and competencies for today's complex healthcare environment. We believe that effective nurse leaders are essential to enable change and create the highly effective systems needed to balance safe, high-quality client care while demonstrating financial accountability. We are in the process of conducting a national and international scan for best practices to educate, develop and support nurse leaders so that they can effectively create environments to support clients, staff and organizations in achieving optimal outcomes.

As well as developing current nursing leaders, we have accountability for building capacity, coaching and mentoring, and to this end we have engaged members in leadership roles outside of the Certified Nurse Educator (CNE) role. As a network, we are working with new leaders aspiring to fulfill the role of nurse executives for the future. In order to build a strong presence in the country, with the ability to influence and be the solution for the system, we must continue to build our membership. Therefore, I encourage all of you to engage in ACEN and support your up-andcoming leaders to become members as well. Our membership drive gets underway in March 2013, and more information will be coming your way soon!

In closing, I want to wish you an enjoyable journey. I feel this is a pivotal moment for nursing in Canada: we're on the threshold of change in healthcare, and the horizon looks promising. We have the opportunity to maximize leadership, promote nursing and engage healthcare practitioners, educators, researchers and policy makers to join us in creating the solutions for tomorrow. I can't guarantee that the sailing will always be smooth, but I know that ACEN will keep the wind in your sails and help you navigate the waters of change.

\section{References}

Lefebre, N. 2012. “All Hands on Deck!” ACEN Update. Canadian Journal of Nursing Leadership 25(3): 18-20.

VanDeVelde-Coke, S., D. Doran, D. Grinspun, L. Hayes, A. Sutherland Boal, K. Velji et al. 2012.

"Measuring Outcomes of Nursing Care, Improving the Health of Canadians: NNQR (C), C-HOBIC and NQuiRE." Canadian Journal of Nursing Leadership 25(2): 26-37. 